\title{
Sources of Inefficiency in Small-Scale Irrigation in Ethiopia: A Stochastic Frontier Analysis
}

Teshager Sisha ( $\nabla$ teshagerassefa@yahoo.com )

Bahir Dar University

\section{Surafel Dillie}

Bahir Dar University

\section{Research Article}

Keywords: Stochastic frontier analysis, Small-scale irrigation, technical efficiency

Posted Date: August 13th, 2021

DOI: https://doi.org/10.21203/rs.3.rs-788145/v1

License: (c) (i) This work is licensed under a Creative Commons Attribution 4.0 International License. Read Full License 


\title{
Sources of Inefficiency in Small-Scale Irrigation in Ethiopia: A Stochastic Frontier Analysis
}

\author{
Teshager Assefa Sisha ${ }^{1}$ and Surafel Melak Dilie ${ }^{2}$
}

\begin{abstract}
Increased production, food security, poverty reduction, and rural economic development can be supported by increasing efficiency in the use of scarce resources and technologies. Promoting small-scale irrigation practices may provide opportunities to improve the efficient utilization of land and labor. This paper assesses the extent of technical efficiencies of two household irrigation technologies: rope \& washer and pulley practiced by farmers in two pilot areas of rural communities in Ethiopia. Stochastic frontier analysis (SFA) was used to estimate efficiency levels and identify the factors affecting inefficiencies. Labor and land are found to have contributed a greater share in the quantity of production of the crops under study. Plough repetition and experience in irrigation also contributed significantly to increased output. The results obtained from the stochastic frontier analysis indicate that farmers are operating at a significantly lower mean efficiency level of 70\%, indicating the existence of room for increased production without additional investment. Distance to the nearest market, female household head, higher dependency ratio and using rope \& washer (compared to pulley) increases the likelihood of being inefficient, whereas higher educational attainment of the head of the household and irrigation experience reduces the probability of inefficiency.
\end{abstract}

Keywords: Stochastic frontier analysis, Small-scale irrigation, technical efficiency

\footnotetext{
${ }^{1}$ Bahir Dar University, Department of Statistics, Ethiopia, teshagerassefa@yahoo.com, (https://orcid.org/00000002-0579-7165)

${ }^{2}$ Bahir Dar university, Department of Economics, Ethiopia, email: msur69@gmail.com
} 


\section{Introduction}

Agriculture is a sector that demands investment priority to reduce much of the poverty in Africa. Since most farmers are smallholders, many of whom are poor, and increases in agricultural output help keep food prices low, small farm-led agricultural development typically has a large impact on poverty [1] and [2]. Empirical studies have provided evidence of this substantial agricultural productivity growth-poverty correlation. For instance, using a cross section of 19 African counties, [3] reported a poverty-yield elasticity of -0.96 . That is, a 1 percent increase in yields decreases the percentage of the population living on less than $\$ 1$ per day by 0.96 percent. Agriculture is also the main source of employment on the continent. For example, Ethiopian agriculture employs twothirds of the nation's labor force, although there was a decline from 80 to 77 percent between 2005 and 2013 [4].

Africa's agriculture is known for its historically low levels of productivity. Increasing productivity is essential to achieve the growth potential of the sector on the continent. Irrigation. Irrigation plays a crucial role in expanding production. Various irrigation schemes can considerably increase crop yields, have the potential to improve livelihoods, provide less exposure to drought risks, encourage an efficient use of limited water resources, and result in greater food production. Irrigation can help to improve and stabilize agricultural productivity, thereby contributing to food security and to resilience against climate change. It also provides year-round farm employment. Depending on the socioeconomic and environmental features of a region, certain irrigation systems have advantages and disadvantages over other systems. Given public financial constraints, poor management of community irrigation schemes and the number of small-farm holders, small-scale irrigation (SSI) is a key strategy to improve productivity in Ethiopia and many Sub-Saharan African countries.

In sub-Saharan Africa, only 4\% of the agricultural land is irrigated. Although an estimated 40 million hectares are suitable for irrigation, only 7.3 million ha are actually irrigated. Madagascar, Nigeria, South Africa, and Sudan are the four countries in which most of the irrigated land is located [5]. As in many sub-Saharan countries, rain-fed agriculture is the dominant farming system of Ethiopian agriculture. Spatially and temporally varying rainfall intensity repeatedly results in incidents of drought, affecting crop and livestock production and contributing to volatility in food prices. When the country is hit by drought, it has devastating consequences resulting in famine and loss of life. 
In Ethiopia, only approximately 4 to 5 percent of the 15 million hectares of cultivated land are irrigated [6]. On the other hand, [7] documented that a significant segment of the population has been suffering from food security for a long period. Given the country's water endowment (12 river basins with an annual runoff volume of 122-billion-meter cube of water and an estimated 2.6 - 2.65-billion-meter cube of groundwater potential), investment in irrigation could substantially serve as a strategy to reduce the negative effect of rainfall variability [8], [9].

\section{Small Scale Irrigation}

SSI affects rural communities in different ways, depending on a number of factors, such as the water source, the relative water availability, the type of technology, access to agricultural inputs, the socioeconomic features of the household, and the institutional rules governing water access and maintenance of water systems. Domenech \& Ringler [10] concluded that SSI generally provides a positive outcome on household income, nutrition, health and women's empowerment.

Privately managed household-level irrigation has been shown to lead to higher productivity and profit margins (Ofosu et al. [11]) and [12] because it avoids problems related to collective action often observed in public or communal irrigation schemes [13]. Studies from sub-Saharan Africa, for example, in Zimbabwe Takeshima et al. [14], Takeshima et al. [15] and Dauda et al. [16], also documented that private irrigation technologies allow smallholder farmers to adjust irrigation schedules to respond to localized events and are more likely to bring higher returns per hectare than community-managed irrigation schemes.

In a study conducted in the Ethiopian highlands by Tucker \& Yirgu [17], small-scale irrigation proved to have promoted rural food security and contributed to poverty alleviation and adaptation to climate change. It enabled households to generate more income, increased their resilience, and in some cases transformed their livelihoods. The poorest households did not benefit much directly, however, and required other support to build up their assets.

\section{Irrigation efficiency}

The literature on technical efficiency in African agriculture is emerging. To our knowledge, empirical evidence on the technical efficiency of household-level irrigation technologies is very limited in Ethiopia. Exceptions are [18], [19], [20], [21], [22], [23] and [24], which have studied irrigation schemes in general. 
For potato-producing farmers of the Awi Zone in Ethiopia, [19] found that the efficiency levels were fairly better, $77 \%$ and $97 \%$ for modern and traditional irrigation schemes, respectively. Using the stochastic production frontier approach, [20] analyzed irrigation systems in the Awash River basin and concluded that the existing irrigation systems are not efficient enough $(55.5 \%$ for Doni and Godino, $76 \%$ for Batu Degaga and $79.8 \%$ for dryland farmers), indicating the need to make the schemes operate near their production frontier. Gebregziabher et al. (2012) performed a comparative efficiency analysis using randomly selected data from smallholder farmers in the Tigray region of Ethiopia between small-scale irrigated and rain-fed agriculture. The study showed that irrigated agriculture suffers from severe inefficiency as low as $45 \%$. Based on a random sample of 434 smallholder farmers in Ethiopia, [25] found the average technical efficiency for modern irrigation schemes to be approximately $71 \%$, whereas this was estimated to be $78 \%$ for rainfed farmers.

In the context of rain-fed agriculture, [18] investigate the technical efficiency of maize producers in Ethiopia and compare the performance of farmers within and outside the Sasakawa-Global $2000^{3}$ project demonstration. Using Cobb-Douglas stochastic production functions, their empirical results show that farmers who participate in the program are more technically efficient (94\%) than those outside the project (79\%). In another rain-fed agricultural study of 385 random samples of southern Ethiopia maize producers, [22] observed the level of efficiency to be as low as 40\%. [24] analyzed the data from smallholder rain-fed maize-producing farmers of the Oromia region of Ethiopia and estimated technical efficiency that ranged from $6 \%$ to $92 \%$ with a mean technical efficiency of $66 \%$. [23] also argued that it is possible to increase wheat production in rain-fed agriculture by $45 \%$ for some selected areas in the Oromia region.

improving efficiency would only be possible if the factors causing inefficiency are identified. These factors can then be altered through policy and other mechanisms. In the literature, socioeconomic and agroecological characteristics have been proven to affect the levels of inefficiencies in irrigated farms.

\footnotetext{
${ }^{3}$ Sasakawa-Global 2000 (SG 2000) is a non-profit organization established to develop programs for technology demonstration in various African countries, in cooperation with national extension services. The SG 2000 project was initiated in Ethiopia during the spring of 1993, in close collaboration with the Ministry of Agriculture of the Transitional Government of Ethiopia and regional bureaus of agriculture.
} 
One important factor that could contribute to productivity and efficiency is education. The existing studies on the determinants of farm productivity and efficiency are largely inconclusive on the question of a positive return to education. Using data from rain-fed maize-producing farmers in eastern Ethiopia [18] confirmed the positive relationship between efficiency and years of schooling. On the other hand, using panel data [26] and [27] fails to identify any significant impact of farmers' education on farming efficiency in India and Java-Indonesia, respectively. However, [23] and [24] found a negative and statistically significant coefficient for education in the efficiency model using rain-fed agriculture data in the Oromia region of Ethiopia.

In many countries, family roles, responsibilities, and rights are gender-related. Women allocate their work time and manage risk differently than men for several reasons. Some of these include the unique child-rearing responsibilities of women and the result of cultural gender roles and differences in access to agricultural productive resources. As a result, it is natural to expect gender differentials in technical efficiency. In rain-fed agriculture, [28] found a significant technical efficiency differential between male (93\%) and female (98\%) maize-producing farmers in Nigeria. On the other hand, using a random sample of rain-fed rice-producing farmers in Ghana [29] found that male-headed households are found to have higher technical efficiency than their female counterparts. Based on data on smallholder rain-fed rice producers in the Ashanti region of Ghana [30], female-headed farms recorded a mean technical efficiency of $16.5 \%$ with a range of between $2 \%$ and $66 \%$. The male-headed farms, on the other hand, showed a mean technical efficiency of $30.8 \%$ and a range between $2 \%$ and $85 \%$.

Using technological inputs to agricultural practices requires additional skills compared to traditional farming practices. During the process of adopting a new practice, it is normal to expect inefficient utilization of resources than one could achieve after becoming familiar with it. Pulley and Rope \& Washer are not equally easy to operate. Rope \& Washer is higher in technological complexity in terms of maintenance and operation relative to pulley.

This study sought to measure the technical efficiency of household-level irrigation technologies and the factors that contribute to inefficiencies. Specifically, it analyzes the technical efficiency of two water lifting technologies that are used to irrigate vegetables and fodder: pulley and rope and washer manual pump. We examined this topic through case studies on irrigated production of tomato, onion, and fodder in two selected areas of the Amhara region in Ethiopia. 


\section{Methodology}

Analytical Framework

The Stochastic Frontier Model

Aigner et al. (1977) related the concept of efficiency to the production frontier four decades ago. Aigner et al. (1977) and Meeusen et al. [32] assumed that the disturbance term, in the general production function model given below, has two components. That is $\epsilon_{i}=v_{i}-u_{i}$

$$
\begin{aligned}
& y_{i}=f(x ; \beta) \times e^{\epsilon_{i}} \\
& y_{i}=f(x ; \beta) \times e^{v_{i}-u_{i}}
\end{aligned}
$$

where $v \sim N\left(0, \delta_{v}^{2}\right)$ and $u \sim N_{+}$and $y$ are the number of output units produced using $x$ input units and $\beta$ are the parameters to be estimated.

The error component $v_{i}$ represents the symmetrical disturbance that captures random errors caused outside the firm's control, such as measurement errors, random shock, and statistical noise. This component is assumed to be identically and independently distributed as $v \sim N\left(0, \delta_{v}^{2}\right)$. The $u_{i}$ component of the error term is the asymmetrical term that captures the technical inefficiency of the observations and is assumed to be independent of $v_{i}$ and to satisfy that $u_{i}>0$. The nonnegative component $\left(u_{i}\right)$ reflects that the output of each firm must be located on or below its frontier [33]. If $u=0$, the firm is $100 \%$ efficient, and if $u>0$, then there is issome inefficiency. [33] stress the need to make some statistical assumptions on the pattern of the values of this term. The assumption of which distributions the $u_{i}$ 's are following can be picked for a variety of reasons, such as ease of use, ease of estimation, level of skewness, number of the parameters, etc. Half-Normal, Truncated Normal, Exponential, and Gamma are among the most commonly assumed distributions. In this study, a half-normal distribution is assumed for simplicity.

Technical efficiency is measured as the ratio of actual production to potential production. Using the models in the stochastic frontier analysis, it can be written as:

$$
\begin{gathered}
T E_{i}=\frac{\text { Actual Production }}{\text { Potential Production }}=\frac{f(x ; \beta) \times e^{v_{i}-u_{i}}}{f(x ; \beta) \times e^{v_{i}}} \\
=e^{-u_{i}}
\end{gathered}
$$


TE takes a maximum value of one because $u_{-} i$ are nonnegative truncated normal.This definition follows from the idea that if a farm household's actual production level is less than the maximum achievable production level that allows the existence of only individual differences, then there is some inefficiency on the part of the farmer.The estimate of $\epsilon_{i}$ carries some information about $u_{i}$. If $\epsilon_{i}>0$, then chances are that $u_{i}$ is not very large, as $E\left(v_{i}\right)=0$, suggesting that production $i$ is relatively efficient. If, on the other hand, $\epsilon_{i}<0$, then $u_{i}$ will tend to be large, suggesting that production $i$ is relatively inefficient. This tells us that the estimate of the (unobserved) efficiency term, $u_{i}$, depends on the (observed) errorterm $\epsilon_{i}$.

The above equation requires us to obtain an estimate of $u_{i}$ for each farm in the sample. From the conditional distribution of $u_{i}$ given $\epsilon_{i}$, we can use the conditional expectation $E\left(u_{i} / \epsilon_{i}\right)$ as an estimator of $u_{i}$.

The joint density of $v_{i}$ and $u_{i}$ is the product of the individual densities, as they are independent

$$
f_{v, u}(v, u)=f_{v}(v) f_{u}(u)
$$

Substituting $\varepsilon+u$ for $v$ we get

$$
f_{\epsilon, u}(\epsilon, u)=f_{v}(\epsilon+u) f_{u}(u) \quad 6
$$

Therefore, using Bayes' theorem, the conditional density of $u$ given $\epsilon$ is:

$$
f(u / \epsilon)=\frac{f_{v}(\epsilon+u) f_{u}(u)}{f_{\epsilon}(\epsilon)}
$$

Here, recall that the functional forms $f_{v}(v), f_{u}(u)$ and $f_{\epsilon}(\epsilon)$ are as assumed at the beginning. That is, they are distributed as Normal, Half Normal and the Convolution of the two. Using this assumption and after some algebraic manipulation, one can arrive at

$$
E(u / \epsilon)=\mu_{*}+\sigma_{*} \frac{\emptyset\left(\mu_{*} / \sigma_{*}\right)}{\Phi\left(\mu_{*} / \sigma_{*}\right)} \quad 8
$$

where $\mu_{*}=-\epsilon \frac{\sigma_{u}^{2}}{\sigma^{2}}=-\epsilon \frac{\lambda^{2}}{1+\lambda^{2}}=-\epsilon \gamma, \sigma_{*}=\sqrt{\frac{\sigma_{u}^{2} \sigma_{v}^{2}}{\sigma^{2}}}=\sigma \frac{\lambda}{1+\lambda^{2}}=\sqrt{\gamma(1-\gamma) \sigma^{2}}, \phi($.$) is the$ density function, and $\Phi($.$) is the cumulative distribution function of a standard normal$ distribution. When we substitute the estimated values for $\epsilon, \sigma^{2}$ and $\lambda$ then we have an estimate of $u$ conditioned on the estimate of $\epsilon$. We, thus get an estimate of TE. 
Technical inefficiency is assumed to be a function of household- and farm-specific variables $z_{i}$ and a set of parameter values to be estimated along with the production function parameters. The inefficiency equation is specified as:

$$
u_{i}=z_{i} \delta_{i}+\alpha_{i}
$$

where $\alpha_{i}$ is a random variable that is assumed to be distributed with mean zero and variance $\sigma_{\alpha}^{2}$. $u_{i}$ is assumed to be the positive half of a normally distributed variable $\left(u_{i} \sim N^{+}\left(0, \sigma_{u}^{2}\right)\right)$. Using the inefficiency equation, we can easily adapt the distribution equations by using the household and farm characteristic variables.

Thus, the truncated normal distribution derived earlier becomes:

$$
f_{u}\left(u_{i}\right)=\frac{1}{\sqrt{2 \pi} \sigma_{u} \Phi\left(z_{i} \delta / \sigma_{u}\right)} \exp \left\{-\frac{\left(u_{i}-z_{i} \delta\right)^{2}}{2 \sigma_{u}^{2}}\right\} \quad u_{i} \geq 0
$$

Similarly, the density function of the random variable $v_{i}$ is given by

$$
f_{v}\left(v_{i}\right)=\frac{1}{\sqrt{2 \pi} \sigma_{v}} \exp \left\{-\frac{v_{i}^{2}}{2 \sigma_{v}^{2}}\right\} \quad-\infty<v_{i}<\infty
$$

With the assumption that the two error components are independently distributed, their joint distribution is simply the product of the above two functions. That is:

$f_{v u}\left(v_{i}, u_{i}\right)=\frac{1}{2 \pi \sigma_{v} \sigma_{u} \Phi\left({ }^{2} \delta / \sigma_{u}\right)} \exp \left\{-\frac{\left(u_{i}-z_{i} \delta\right)^{2}}{2 \sigma_{u}^{2}}-\frac{v_{i}^{2}}{2 \sigma_{v}^{2}}\right\} \quad-\infty<v_{i}<\infty, \quad u_{i} \geq 0$

The distribution of $\epsilon_{i}=v_{i}-u_{i}=y_{i}-f\left(x_{i}, \beta_{i}\right)$ is derived, either from the joint distribution of $\epsilon_{i}$ and $u_{i}$ or from the convolution of the distributions of $v_{i}$ and $u_{i}$, as:

$$
f_{\epsilon}\left(\epsilon_{i}\right)=\frac{1}{\sqrt{2 \pi}\left(\sigma_{v}^{2}+\sigma_{u}^{2}\right)^{1 / 2}\left[\Phi\left(z \delta / \sigma_{v}\right) / \Phi\left(\mu^{*} / \sigma_{*}\right)\right]} \exp \left\{-\frac{\left(u+\epsilon_{i}\right)^{2}}{2\left(\sigma_{v}^{2}+\sigma_{u}^{2}\right)}\right\}
$$

Where, $\mu^{*}=\left(\sigma_{v}^{2} z \delta-\sigma_{u}^{2} \epsilon\right) /\left(\sigma_{v}^{2}+\sigma_{u}^{2}\right)$ and $\sigma_{*}^{2}=\left(\sigma_{v}^{2} \times \sigma_{u}^{2} /\left(\sigma_{v}^{2}+\sigma_{u}^{2}\right)\right.$.

Therefore the density function of $y_{i}$ becomes;

$$
f_{y}\left(y_{i}\right)=\frac{1}{\sqrt{2 \pi}\left(\sigma_{v}^{2}+\sigma_{u}^{2}\right)^{1 / 2}\left[\Phi\left(\tilde{\mu}_{i}\right) / \Phi\left(\tilde{\mu}_{i}^{*}\right)\right]} \exp \left\{-\frac{\left(y_{i}-f\left(x_{i}, \beta\right)+z_{i} \delta\right)^{2}}{2\left(\sigma_{v}^{2}+\sigma_{u}^{2}\right)}\right\}
$$

Where, $\tilde{\mu}_{i}=z_{i} \delta / \sigma_{u}$ and $\tilde{\mu}_{i}^{*}=\left[\sigma_{v}^{2} z_{i} \delta-\sigma_{u}^{2}\left(y_{i}-f\left(x_{i}, \beta\right)\right)\right] / \sigma_{*}\left(\sigma_{v}^{2}+\sigma_{u}^{2}\right)$ 
The log-likelihood function for a sample of $\mathrm{n}$ observations thus becomes:

$$
\begin{aligned}
\mathcal{L}\left(\beta, \delta, \sigma_{v}^{2}, \sigma_{u}^{u}, y\right) & \\
= & -\frac{1}{2}\left[\left(\sum_{i=1}^{n} \ln 2 \pi+\ln \sigma^{2}\right)+\left(\sum_{i=1}^{n} y_{i}-f\left(x_{i}, \beta\right)+z_{i} \delta / \sigma^{2}\right)\right. \\
& \left.+\left(\ln \Phi\left(\tilde{\mu}_{i}\right)-\ln \left(\tilde{\mu}_{i}^{*}\right)\right)\right]
\end{aligned}
$$

The Cobb-Douglas specification is used for the estimation of the stochastic production frontier. In logarithmic form with variables under consideration, the specification has the following form:

$$
\begin{aligned}
\text { InYield }_{i}= & \beta_{0}+\beta_{1} \text { Inplot }_{i}+\beta_{2} \text { Inlabor }_{i}+\beta_{3} \text { ploughrept }_{i}+\beta_{4} \text { Croptype }_{i}+ \\
& \beta_{5} \text { Technotype }_{i}+\beta_{6} \text { irrexper }+\beta_{7} \text { irrexpersqrd }_{+} \beta_{8} \text { Technoype }_{i} * \text { Gender }_{i}+ \\
& \beta_{9} \text { Tecnotype }_{i} * \text { Site }_{i}
\end{aligned}
$$

where yield (in $\mathrm{kg} / \mathrm{hectare}$ ) is the quantity of vegetables and/or fodder harvested, plot is the size of the land, in hectares, irrigated using the particular irrigation technology, labor, in man-days per hectare is the total labor employed from plot preparation all the way to harvest. Croptype is the type of crop cultivated (tomato=1, onion=2 and elephant grass=3). Technotype $(\mathrm{Pulley}=1$ and Rope $\&$ washer =2) is the type of water lifting technology used for irrigation. irrexper the number of years the farmers engaged in irrigated farming prior to the intervention. Ploughrept (the number of times the plot is plowed before planting the crop) is included in the production function with the assumption that it contributes positively to increased production. Site is the two research sites (Robit $=1$ and Dangila =2). Finally, a value of 0 is assigned for females and 1 for males for the variable Gender. The interaction effects are considered in this model based on the practical observations of the researchers at the sites where these water lifting technologies seem to depend on who actually is operating them. For some segment of the farmers, the technologies are new and appear to require some time to adapt, while for others, they use them for better production.

A simple linear model is used for the inefficiency equation, that is, the equation that specifies the determinants for the inefficiency term is:

$u_{i}=+\delta_{1}$ croptype $+\delta_{2}$ dependration $+\delta_{3}$ irrexper $+\delta_{4}$ Gender $+\delta_{5}$ technotype + $\delta_{6} e d u h h+\delta_{7}$ mrktdist $+\alpha_{i}$ 
where dependratio is the dependency ratio (percentage of the family members in the household who are aged under 15 and over 65) and mrktdist is the distance (Km) of the household from the nearest market.

Data

This study is based on data drawn from the two research sites of the Feed the Future (FtF) Innovation Laboratory for Small-Scale Irrigation (ILSSI) in Ethiopia. These include Robit and Dangila in Amhara region. (Figure 1)

Dangila is located approximately 80 kilometers southwest of Bahir Dar. In the woreda, there are 27 rural Kebeles, among which 16 have access to perennial rivers. The average annual rainfall is approximately $1600 \mathrm{~mm}$ but varies between $1180-2000 \mathrm{~mm}$.

Robit is located $10 \mathrm{~km}$ north of Bahir Dar. It has a sub-tropical ("Woina Dega") climate. Cereal and high-value irrigated crop production are common in the area. Experience in smallholder irrigation and groundwater potential are relatively high. Motor pumps and manual water lifting technologies are commonly used in the kebele. Approximately 4000 wells are observed in the kebele. In addition to shallow groundwater, river diversion and lake pumping are sources of irrigation water. In 2014, approximately 1820 ha. of land was irrigated. About $85 \%$ of the irrigated land use motor pumps.

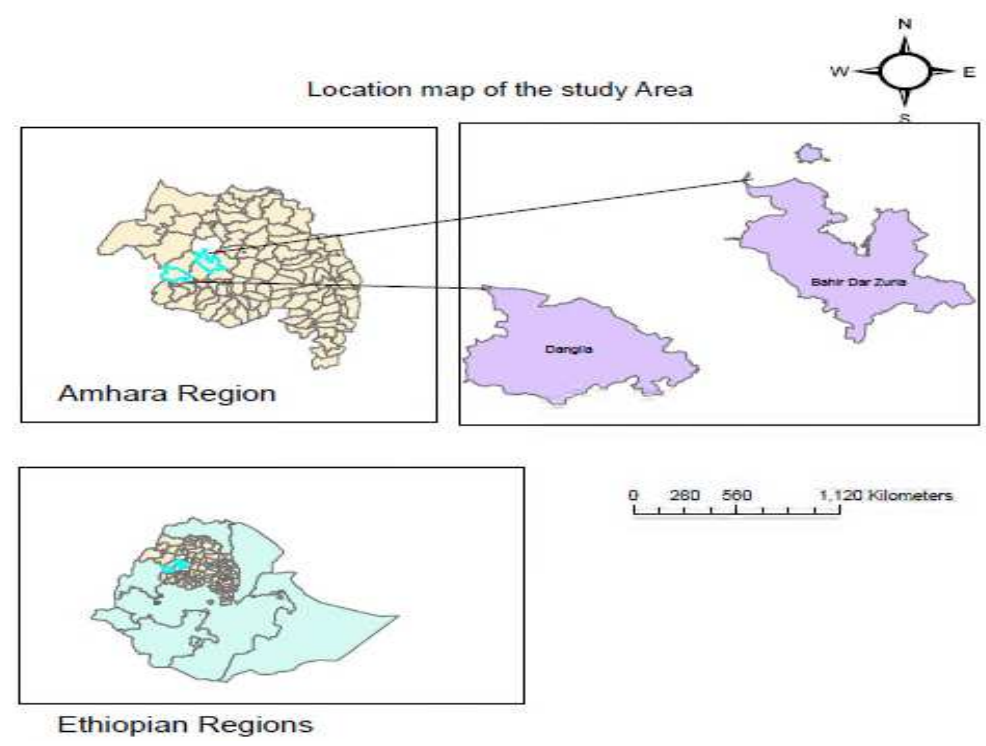

Figure 1: Map of the study area 
From the above two purposely selected areas, 54 target households were selected by the local administrators and community leaders of the respected areas within the areas whose farms reside in Dengeshita and Robit Wotersheds. For these target households (22 from Dangila kebele and 32 from Robit kebele), two irrigation technologies (Rope-and-Washer and Pulley) were made available on a credit basis with which they cultivated a common crop (Tomato and elephant grass in Robit and onion in Dangila) during the 2014/2015 dry season (Table 1). 33\% of the farms under the experiment were owned by female household heads. The irrigated plot sizes ranged from 50meter squares to 250-meter squares.

Table 1: Distribution of technologies

\begin{tabular}{lrrr} 
& Robit & Dangila & Total \\
\hline Pulley & 20 & 11 & $\mathbf{3 1}$ \\
Rope \& washer & 12 & 11 & $\mathbf{2 3}$ \\
Total & $\mathbf{3 2}$ & $\mathbf{2 2}$ & $\mathbf{5 4}$ \\
\hline
\end{tabular}

These farms enjoyed a close follow-up of different agricultural professionals. Irrigation experts visited the plots repeatedly to help farmers apply the optimum amount of water. Frequent technical support for the use and maintenance of irrigation technologies was given by supplier and graduate students. For tomato producers, as it is a new variety for local farmers, agronomists provided detailed on-field training on how to plant it with proper spacing, water application for disease control and harvest-related activities. Local agricultural extension workers were also in frequent contact from nursery preparation to harvest. Financial literacy training and close follow-up of their saving behaviour were also part of the support these farmers benefited from. these research project.

A number of data collection instruments were employed. Before the intervention, baseline data were collected using a semistructured questionnaire and focus group discussions to capture information about the socioeconomic and demographic characteristics as well as agronomic practices of the household members. The field book used to collect data related to agronomic practices and related costs helped capture information on family nutrition, the economic status of the targeted households and gender aspects of small-scale irrigation. 
A hybrid seed (Shanty F1) was used for tomato cultivation, and a local seed was used for onion cultivation. The hybrid seed is expensive (2077 Birr 4 /hectare) compared to the local seed. The new variety, though less resistant to disease, provided farmers with higher yields and demand in the market. Irrigated fodder is not practiced in the study area. Farmers were willing to cultivate it for domestic consumption (not for marketing) only on smaller plots (average of $10 \mathrm{~m}^{2}$ ). This animal feed is harvested repeatedly in a single irrigation season, and the aggregate is used for the estimation of the production frontier. The farmers in this category (irrigated fodder) are observed to have no irrigation experience for the production of fodder.

\section{Results}

Table 2 is a summary of all the variables considered in the analysis. The different categories used, technology type, crop type, gender and site of the experiment would help to clarify the results of the analysis from our basic model.

\footnotetext{
${ }^{4} 1$ USD was equivalent to about 21 Ethiopian Birr by that time
} 
Table 2: Average values of variables explored in the analysis.

\begin{tabular}{|c|c|c|c|c|c|c|c|c|c|}
\hline & \multicolumn{2}{|c|}{ Technology Type } & \multicolumn{3}{|c|}{ Crop type } & \multicolumn{2}{|c|}{ Gender } & \multicolumn{2}{|c|}{ Location } \\
\hline & Pulley & Rope \& & Onion & Tomato & Fodder & Male & Female & Robit & Dangila \\
\hline & $\mathbf{n}=\mathbf{3 1}$ & Washer $n=23$ & $n=22$ & $\mathrm{n}=\mathbf{1 7}$ & $n=15$ & $m=36$ & $n=18$ & $\mathrm{n}=\mathbf{3 2}$ & $\mathrm{n}=\mathbf{2 2}$ \\
\hline Yield (Kg/Hectare) & 11665.67 & 8291.128 & 2909.145 & 11449.97 & 19578.73 & 10780.08 & 9124.918 & 15260.32 & 2909.145 \\
\hline Plot size (Hectare) & .014 & .013 & .015 & .015 & .009 & .013 & .014 & .012 & .015 \\
\hline Labor (man-days/Hec) & 1505.02 & 1722.85 & 1596.25 & 1080.30 & 2186.58 & 1367.08 & 2059.24 & 1598.86 & 1596.25 \\
\hline Fertilizer (Kg/Hec) & .36 & .26 & .49 & .20 & .20 & .30 & .34 & .20 & .49 \\
\hline Cost of Seed (Birr/Hec) & 5217.48 & 5897.68 & 8504.61 & 2075.70 & 5000 & 5369.72 & 5782.14 & 3446.47 & 8504.61 \\
\hline Education (years) & 1.58 & 2.22 & 2.63 & 1.88 & 0.67 & 3.38 & 2.45 & 2.67 & 3.49 \\
\hline Land Holding (Hectare) & 1.27 & 1.53 & 1.20 & 1.48 & 1.55 & 1.58 & 1.00 & 1.51 & 1.20 \\
\hline Livestock Holding (TLU) & 5.35 & 4.86 & 5.93 & 4.29 & 4.95 & 6.21 & 3.00 & 4.60 & 5.93 \\
\hline Market distance (Km) & 1.31 & 1.54 & 1.40 & 1.47 & 1.33 & 1.44 & 1.33 & 1.41 & 1.40 \\
\hline Age (Years) & 39.39 & 45.61 & 42.23 & 37.41 & 47.00 & 21.03 & 23.44 & 21.38 & 23.03 \\
\hline Farm income (Eth. Birr) & 35687.58 & 22133.48 & 12021.36 & 31506.47 & 54353.67 & 37755.56 & 14232.5 & 42216.09 & 12021.36 \\
\hline Irrigation experience (years) & 2.74 & 2.87 & 3.64 & 4.18 & 0 & 2.70 & 3 & 2.22 & 3.64 \\
\hline Labor to Yield ratio & 0.45 & 0.53 & 0.92 & 0.24 & 0.12 & 0.35 & 0.74 & 0.18 & 0.92 \\
\hline
\end{tabular}


An important socioeconomic variable that could affect efficiency in production is education. As is the case in the rural areas of the country, the educational attainment level of the farmers under the experiment is as low as 2 years of schooling on average (Figure 2). In this experimental study, approximately $84 \%$ of the Robit farmers and $50 \%$ of Dangila farmers were illiterate. According to the third national socioeconomic survey performed by the World Bank in 2015 (ERSS wave 3), the literacy rate in the rural community was approximately 39\%, and the gender differential was very high (48\% for men and $17.5 \%$ for women). Dangila beneficiaries are relatively better educated, having an average of approximately 5 years of schooling.

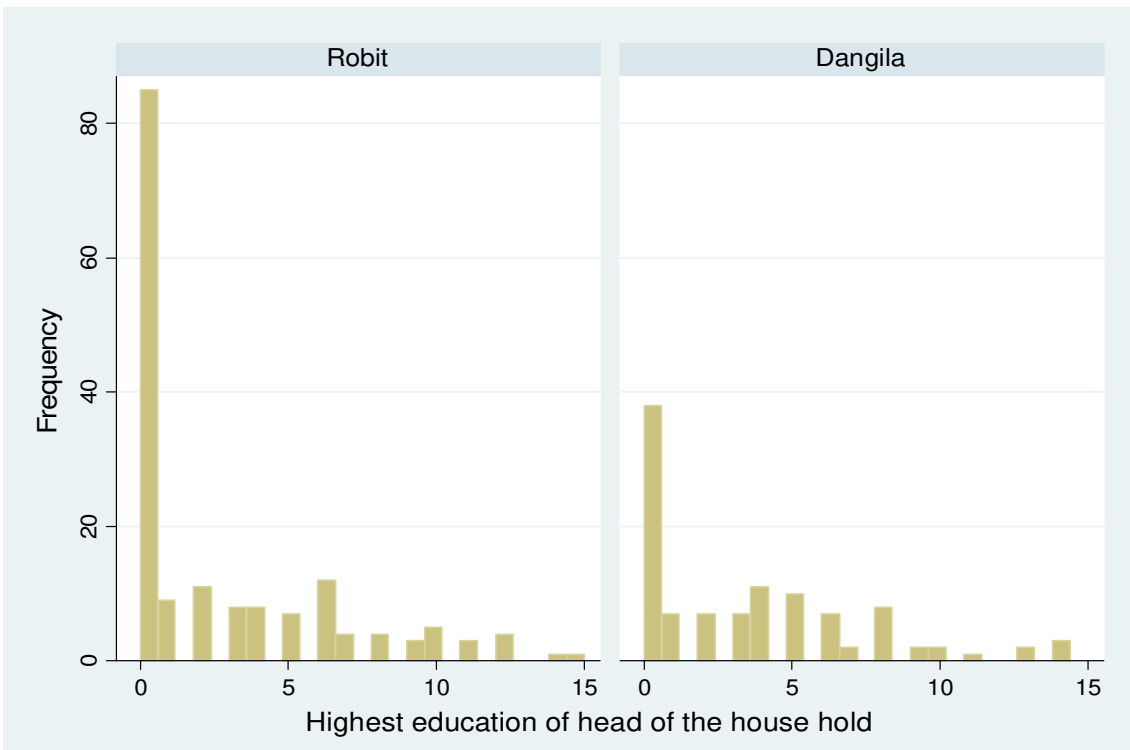

Figure 2: Education level of the head of the household in the experiment

\section{Production function estimates}

Table 3 summarizes the coefficient estimates of the production function described above (equation 10). The estimates are obtained using maximum likelihood estimation techniques with 54 observations. Only significant $(\mathrm{p}<0.05)$ coefficients are reported here.

Farmers who cultivated onion produced not only much below the standard yield, 350-450 quintals/hectare [34] level but also less than those who chose to cultivate tomato. 
For onion producers, the labor-to-yield ratio observed is much higher than that of the tomato crop. It seems that onion-producing farmers used their technology, labor, and other resources inefficiently.

Table 3: Maximum likelihood estimates of stochastic production function parameters (Eq. 10)

\begin{tabular}{lrr}
\hline & Coefficient & p-value \\
\hline Amount of labor employed & 0.392 & 0.000 \\
Area of cultivated land & 0.381 & 0.001 \\
Crop type cultivated & 0.207 & 0.002 \\
Experience in irrigation & 0.059 & 0.030 \\
Plough repetition & 0.022 & 0.009 \\
Experience squared & -0.235 & 0.000 \\
Technology type with Location & & \\
$\quad$ Robit*Rope \& washer & 0.473 & 0.012 \\
$\quad$ Dangila*Pulley & -2.373 & 0.000 \\
$\quad$ Dangila*Rope \& washer & -1.052 & 0.000 \\
Technology type with Gender & & \\
$\quad$ Female*Rope \& washer & -0.745 & 0.026 \\
$\quad$ Male*Pulley & 0.829 & 0.000 \\
$\quad$ Male*Rope \& washer & -0.008 & 0.000 \\
Constant & & \\
\hline
\end{tabular}

Amount of labor invested, measured in man-days per hectare, takes the largest share in contributing to the production of vegetables and/or fodder. This, theoretically, is an obvious result, as production is an immediate outcome of labor. The coefficient estimate of labor implies that a $10 \%$ increase in the amount of labor would increase yield by approximately $4 \%$, ceteris paribus.

Parameter estimates of the size of cultivated land also indicate the irreplaceable importance of scarce resources in the production process. The estimated coefficient carried a positive sign that indicates that a larger plot area is associated with additional production. In fact, each additional percentage increment in cultivated area contributes approximately $0.38 \%$ of the aditional production on average. The estimated coefficient for experience in irrigation in our model also depicts the fact that productivity rises with increases in experence but eventually shows a decline. 
Two interaction effects are included in the model: technology type with gender and site based on a priori information in the area. Farmers at robit sites are less adaptive to rope and washers, and those in dangila are efficient in using them; the opposite happents to be true for Pulley. Women in both research sites were observed to have made efficient use of pulley compared with rope\&washer

Ploughing repetition is included in the model because of the general assumption that crop productivity is highly and positively correlated with this kind of land preparation activity. All the variables included in the model resulted in the expected sign at the $95 \%$ level of significance except for the amount of fertilizer and seed used, which appeared statistically insignificant and are not reported here.

\section{Efficiency estimates}

The results from the SFA model indicate that there are farmers who suffer from inefficiency levels as low as $51 \%$. The average technical efficiency level is approximately $70 \%$ (Figure 3 ).

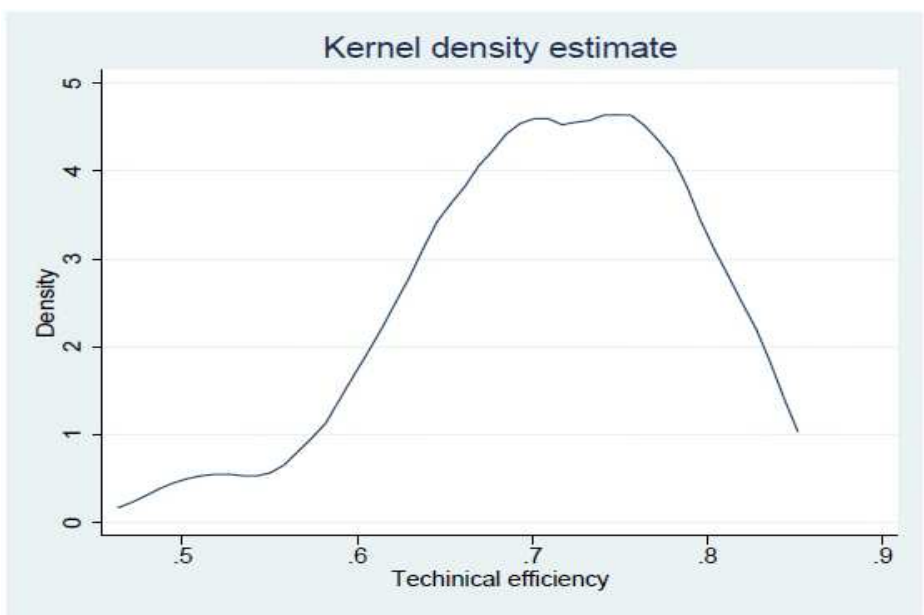

Figure 3. Kernel density of technical efficiency

The efficiency estimate result indicates the existence of significant room for improvement by approximately $30 \%$ using existing resources (Table 4).

Women- and men-headed households in the study area generally appear to have no difference in efficiency levels (Table 5). However, when looking at disaggregation based on the type of crop cultivated and different experimental sites, a lower efficiency level is observed for women-headed households (Table 5: Efficiency of all sample 


\begin{tabular}{lrrccc}
\hline & mean & St.dev. & min & max & N \\
\hline Female & 0.70 & 0.07 & 0.53 & 0.81 & 18 \\
Male & 0.70 & 0.08 & 0.49 & 0.82 & 36 \\
Total & 0.70 & 0.08 & 0.49 & 0.82 & 54 \\
\hline
\end{tabular}

Table 6 and Table 7), except for fodder irrigators. An average efficiency level of $76 \%$ is recorded for women-headed households who are engaged only in the production of fodder, compared to only $70 \%$ for their male-headed fodder farmers.

Table 4: Efficiency for fodder farmers.

\begin{tabular}{lrrccr}
\hline & mean & St.dev. & min & $\max$ & \multicolumn{1}{c}{$\mathbf{N}$} \\
\hline Female & 0.76 & 0.03 & 0.73 & 0.80 & 5 \\
Male & 0.70 & 0.05 & 0.62 & 0.81 & 10 \\
Total & 0.72 & 0.05 & 0.62 & 0.80 & 15 \\
\hline
\end{tabular}

Table 5: Efficiency of all sample

\begin{tabular}{lrrccc}
\hline & mean & St.dev. & min & $\max$ & $\mathbf{N}$ \\
\hline Female & 0.70 & 0.07 & 0.53 & 0.81 & 18 \\
Male & 0.70 & 0.08 & 0.49 & 0.82 & 36 \\
Total & 0.70 & 0.08 & 0.49 & 0.82 & 54 \\
\hline
\end{tabular}

Table 6: Efficiency for vegetable farmers

\begin{tabular}{lrrccc}
\hline & mean & St.dev. & min & max & N \\
\hline Female & 0.68 & 0.07 & 0.53 & 0.81 & 13 \\
Male & 0.71 & 0.08 & 0.49 & 0.82 & 26 \\
Total & 0.70 & 0.08 & 0.49 & 0.82 & 39 \\
\hline
\end{tabular}

Table 7: Efficiency of Robit farmers by gender

\begin{tabular}{lrrcrl}
\hline & mean & St.dev. & min & $\max$ & $\mathbf{N}$ \\
\hline Female & 0.70 & 0.08 & 0.53 & 0.8 & 10 \\
Male & 0.72 & 0.06 & 0.61 & 0.82 & 22 \\
Total & 0.71 & 0.07 & 0.53 & 0.82 & 32 \\
\hline
\end{tabular}


For Rope-and-washer users, the severity of inefficiency is relatively higher than farmers who used a pulley (Figure 4). This could be due to the more intensive labor and technical skills requirements of the technology. This problem is even more severe for Robit farmers, probably because the opportunity cost of labor is higher (Table 8 vs ).

Table 8: Efficiency of Robit Farmers by technology

\begin{tabular}{lrrrrc}
\hline & mean & St.dev. & min & max & N \\
\hline Pulley & 0.73 & 0.06 & 0.6 & 0.82 & 20 \\
R\&W & 0.68 & 0.07 & 0.53 & 0.81 & 12 \\
Total & 0.71 & 0.07 & 0.53 & 0.82 & 32 \\
\hline
\end{tabular}

Table 9: Efficiency of Dangila farmers

\begin{tabular}{lrrrrr}
\hline & mean & St.dev. & min & max & N \\
\hline Pulley & 0.65 & 0.07 & 0.49 & 0.74 & 11 \\
R\&W & 0.73 & 0.06 & 0.6 & 0.81 & 11 \\
Total & 0.69 & 0.08 & 0.49 & 0.81 & 22 \\
\hline
\end{tabular}

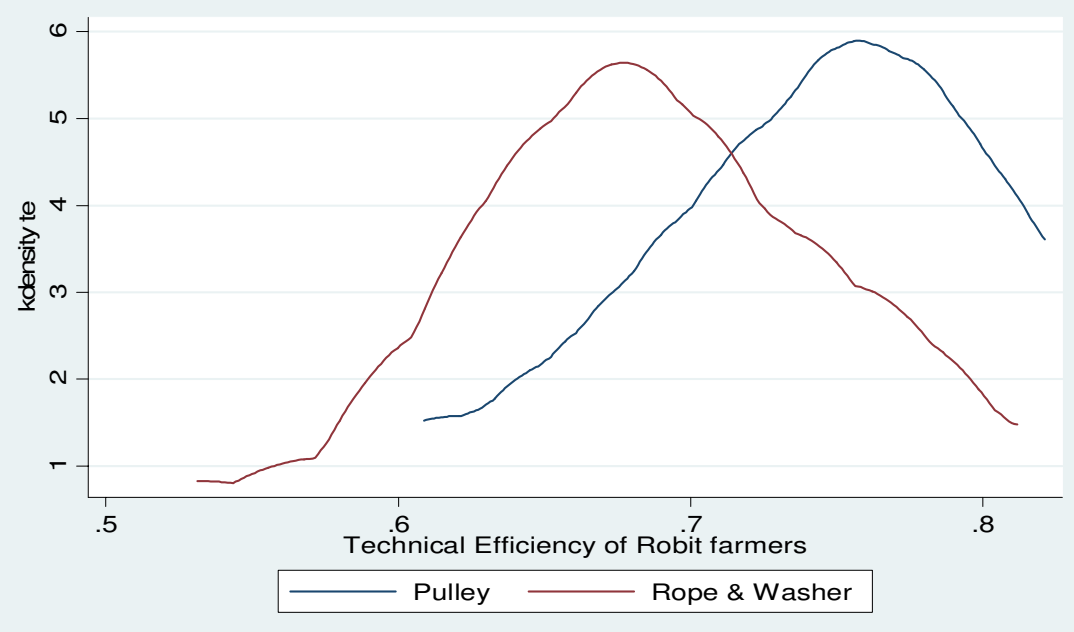




\section{Determinants of inefficiency}

The inefficiency equation (Eq. 11) estimates indicated that inefficiency in using the two water lifting technologies is due to several socioeconomic and demographic variables. Table 10 shows the coefficients of the variable included in the inefficiency equation. Since the dependent variable in the inefficiency equation is inefficiency, the negative sign of the coefficient of a variable indicates that the variable contributes positively to efficiency in production and vice versa.

Table 10: Maximum likelihood estimate efficiency equation parameters.

\begin{tabular}{lrr}
\multicolumn{1}{c}{ Variables } & Coefficients & P-value \\
\hline Dependency ration & 1.43 & 0.002 \\
Education of household head & -1.35 & 0.031 \\
Crop type cultivated & -0.17 & 0.002 \\
Type of irrigation technology installed & 2.18 & 0.000 \\
Irrigation experience & -0.23 & 0.012 \\
Sex of household head & 0.60 & 0.001 \\
Distance from market & 0.52 & 0.022 \\
\hline sigma_u & 0.561 & 0.010 \\
sigma_v & 0.512 & 0.000 \\
lambda & 1.097 & 0.002 \\
Average efficiency & 0.702 & \\
Log likelihood & -52.81 & \\
\hline
\end{tabular}

According to the estimated coefficients, we see that the choice of technology matters for the level of technical efficiency. The positive and significant coefficient (2.18) for technology type (Pulley=1 and Rope \& Washer=2) indicates that Rope \& Washer users are less efficient than pulley users. All the farmers in Robit Kebele who took rope and washer were dissatisfied and had discontinued using them, probably due to the depth of water and high level of labor requirements. Labor is very expensive in Robit compared to Dangila, most likely due to the proximity of Robit to Bahir-Dar city, where employment opportunities are relatively abundant and wage rates are high. This implies that a blanket recommendation of technology adoption 
is not appropriate, implying that "one does not fit all". Hence, identifying and choosing an appropriate technology that is suitable to a particular environment to improve efficiency in production.

In theory, experience in irrigation is believed to have a positive impact on efficiency. The coefficient estimate at the 5\% level of significance also underlines the importance of experience in farmer performance. Irrigation using other sources of water, such as rivers, helped them acquire skills important for increased production.

Education, which serves as a proxy for managerial skills, was found to have a negative and significant (at the 5\% significance level), implying that a higher level of education may lead to higher efficiency due to their ability to better manage their farms, including the efficient use of inputs. It is believed that education increases human capital and contributes positively to changing farmers' attitudes towards modern technology. In addition, education enhances a farmer's ability to make good use of information. As a result of intensive support provided by the project, the impact of education and the levels of income they obtained from farm activities seem to have significant effects on the efficiency levels. The lower education level, for some segment of the farmers in the sample, also played a role in making them unable to invest their scarce resources in a way that they could achieve the maximum attainable production. Thus, it could be used as an input for a policy favoring the expansion of education in rural areas and to encourage parents to send their children to school.

Sex of the head of the household ( 0 for women and 1 for men) was included to examine whether gender impacts efficiency. The estimated coefficient tells us that male-headed households are slightly more efficient than female-headed households. This could be due to limited access to information facing Ethiopian rural women. Labor is more likely to be limited to female-headed households compared to men-headed counterparts. Women have additional responsibility for taking care of other in-home activities, and farming is a secondary concern that they do not give as much attention as men.

To see the effect of the availability and proximity of infrastructure on irrigated farming efficiency, distance to the nearest market was included in the model. The estimated coefficient implies that farmers who must travel longer distances to marketplaces are less efficient. This 
could be due to the long time they spend traveling to marketplaces could be spent taking care of their plots.

The coefficient estimates for the type of crop cultivated gave a statistically significant result, which shows that farmers cultivating animal fodder are more efficient than vegetable producers. Here, it should be noted that the measurement of yield in this animal feed includes all the biomass, while vegetables do not. This measurement difference might contribute to the inefficiency difference result of our model. This variable is included to control this measurement difference in estimating the remaining variable coefficients. Tomato producers are least efficient among the crops under consideration. This could be attributed to the new variety seed used, which suffered from repeated disease during the experiment.

The dependency ratio is included in the inefficiency model with the assumption that this variable would tell us some effect on the efficiency level of the household in irrigated agriculture. This variable, the portion of in-active family members, is a burden to the household. The estimated coefficient also supports the idea that households with a high dependency ratio are found to exhibit a less efficient production process. This is due to the higher share of labor time going to caring members of the household who need it and less labor time going to caring the farm plots.

\section{Conclusions}

The paper utilized experimental data to analyze the technical efficiency of smallholder farmers who adopt household irrigation technologies to produce irrigated vegetables and fodder. Our findings indicate that household irrigation agriculture at the two experimental sites is only moderately efficient. Rope and washer users are less efficient than pulley users, probably due to a wide range of factors, such as labor use, knowledge, experience in irrigation and socioeconomic and demographic factors. Efficiency also varies over crop type cultivated

It should be noted that inefficiency is a loss for a producer. Being unable to produce to the level potentially possible is something that should take attention first. This may be done by providing continuous capacity building to farmers for better allocation of their scarcer resources and labor time. The option of producing at least twice a year would also contribute to reducing the loss resulting from inefficiency. Second, extension support in identifying the 
right mix of crops and technology may improve the production and productivity of farmers. Moreover, farmers with less irrigation experience can increase their productivity if they can acquire skills from experienced farmers. This can be continuously coordinated by local development agents.

Finding the right technology for the right context and user is also another important message decision maker should consider. Technologies uses are dependent on who is using it. Women prefer pulley over Rope and Washer. Likewise, farmers in Dangila prefer to use rope and washer rather than pulley.

To increase production by a significant amount, policies promoting small scale irrigation should also consider, among other things, rural development strategies such as promoting education, family planning, creating access to markets.

\section{Data availability}

The datasets generated during and/or analyzed during the current study are available from the corresponding author on reasonable request.

\section{Reference}

[1] Tshilidzi Madzivhandila, S. Sibanda, and F. A. Gwelo, "Africa Agriculture Status Report 2016," Africa Agriculture Status Report 2016, p. 19, 2016, doi: http://hdl.handle.net/10568/42343.

[2] FAO, "Irrigation market brief," 2015.

[3] L. Lin, V. Mckenzie, J. Piesse, and C. Thirtle, "Africa Agriculture Status Report," 2017. doi: 10.1016/j.ultsonch.2013.05.009.

[4] World Bank, “Ethiopia's Great Run,” 2016.

[5] J. A. Burney, R. L. Naylor, and S. L. Postel, "The case for distributed irrigation as a development priority in sub-Saharan Africa," Proceedings of the National Academy of Sciences, vol. 110, no. 31, pp. 12513-12517, 2013, doi: 10.1073/pnas.1203597110.

[6] S. B. Awulachew, T. Erkossa, and R. E. Namara, "Irrigation potential in Ethiopia: Constraints and opportunities for enhancing the system," International Water Management Institute, no. July, pp. 1-59, 2010.

[7] T. A. Sisha, "Household level food insecurity assessment: Evidence from panel data, Ethiopia," Scientific African, vol. 7, Mar. 2020, doi: 10.1016/j.sciaf.2019.e00262. 
[8] G. Gebregziabher et al., "Does investment in motor pump-based smallholder irrigation lead to financially viable input intensification and production ? An economic assessment," LIVES Working Paper 13, 2016.

[9] S. B. Awulachew, A. D. Yilma, M. Loulseged, W. Loiskandl, M. Ayana, and T. Alamirew, Water resources and irrigation development in Ethiopia, vol. 123. Iwmi, 2007.

[10] L. Domenech and C. Ringler, "The Impact of Irrigation on Nutrition, Health, and Gender: A Review Paper With Insights for Africa South of the Sahara," SSRN Electronic Journal, no. April, 2013.

[11] E. A. Ofosu, P. van der Zaag, N. C. van de Giesen, and S. N. Odai, "Productivity of irrigation technologies in the White Volta basin," Physics and Chemistry of the Earth, vol. 35, no. 13-14, pp. 706-716, 2010, doi: 10.1016/j.pce.2010.07.005.

[12] G. D. Souza and J. Ikerd, "Small Farms and Sustainable Development : Is Small More Sustainable ?," Journal of Agriculture and Applied Economics, 281 (July 1996), vol. 1, no. Ju1Y, pp. 73-83, 1996, doi: 10.1017/S1074070800009470.

[13] C. De Fraiture and M. Giordano, "Small private irrigation: A thriving but overlooked sector," Agricultural Water Management, vol. 131, pp. 167-174, 2014, doi: 10.1016/j.agwat.2013.07.005.

[14] H. Takeshima, A. Adeoti, and S. Okoli, "Demand characteristics for small-scale private irrigation technologies: Knowledge gaps in Nigeria," IFPRI Nigeria, 2010.

[15] H. Takeshima, A. I. Adeoti, and S. Salau, "Measuring the effect of transaction costs for investment in irrigation pumps: Application of the unobserved stochastic threshold model to the case of Nigeria," AfJARE, vol. 6, no. 2, 2011.

[16] T. O. Dauda, O. E. Asiribo, S. O. Akinbode, J. O. Saka, and B. F. Salahu, "An assessment of the roles of irrigation farming in the millennium development goals," African Journal of Agricultural Research, vol. 4, no. 5, pp. 445-450, 2009.

[17] J. Tucker and L. Yirgu, "Small-scale irrigation in the Ethiopian highlands," no. 3, pp. 1-4, 2010.

[18] E. T. Seyoum, G. E. Battese, and E. M. Fleming, "Technical efficiency and productivity of maize producers in eastern Ethiopia: A study of farmers within and outside the Sasakawa-Global 2000 project," Agricultural Economics, vol. 19, no. 3, pp. 341-348, 1998, doi: 10.1016/S01695150(98)00037-1.

[19] T. Bogale and A. Bogale, "Technical efficiency of resource use in the production of irrigated potato: a study of farmers using modern and traditional irrigation schemes in Awi Zone, Ethiopia," Journal of Agriculture and Rural Development in the, 2005.

[20] D. Kelemework, "A comparative analysis of the technical efficiency of irrigated and rainfed agriculture: a case of Awash and Rift valleys of Ethiopia," 2008.

[21] G. Gebregziabher, R. E. Namara, and S. Holden, "Technical efficiency of irrigated and rain-fed smallholder agriculture in Tigray, Ethiopia: A comparative stochastic frontier production function analysis," Quarterly Journal of International Agriculture, vol. 51, no. 3, pp. 203-226, 2012. 
[22] E. Geta, A. Bogale, B. Kassa, and E. Elias, "Productivity and efficiency analysis of smallholder maize producers in Southern Ethiopia," Journal of Human Ecology, 2013.

[23] M. Yami, T. Solomon, B. Begna, and F. Fufa, "Source of technical inefficiency of smallholder wheat farmers in selected waterlogged areas of Ethiopia: A translog production function approach," African Journal of Agricultural Research, vol. 8, no. 29, pp. 3930-3940., 2013.

[24] G. Kitila and B. Alemu, "Analysis of Technical Efficiency of Small Holder Maize Growing Farmers of Horo Guduru Wollega Zone, Ethiopia: A Stochastic Frontier Approach," Science, Technology and Arts Research Journal, vol. 3, no. 3, p. 204, 2014, doi: 10.4314/star.v3i3.33.

[25] G. Makombe, R. E. Namara, S. B. Awulachew, F. Hagos, M. Ayana, and M. Kanjere, "An analysis of the productivity and technical efficiency of smallholder irrigation in Ethiopia," Water SA, vol. 43, no. 1,2017 , doi: $10.4314 /$ wsa.v43i1.08.

[26] T. Coelli and G. Battese, "A Model for Technical Inefficiency Effects in a Stochastic Frontier Production function for Panel Data," Empirical Economics, no. 20, pp. 325-332, 1995.

[27] R. Llewelyn and J. Williams, "Nonparametric analysis of technical, pure technical, and scale efficiencies for food crop production in East Java, Indonesia," Agricultural Economics, 1996.

[28] J. B. Simonyan, B. D. Umoren, and B. C. Okoye, "Gender differentials in technical efficiency among maize farmers in Essien Udim local government area, Nigeria," International Journal of Economics and Management Sciences, vol. 1, no. 2, pp. 17-23, 2011.

[29] M. Addison, K. Ohene-Yankyera, and E. Fredua-Antoh, "Gender Role , Input Use and Technical Efficiency among Rice Farmers at Ahafo Ano North District in Ashanti Region of Ghana," Journal of Food Security, vol. 4, no. 2, pp. 27-35, 2016, doi: 10.12691/jfs-4-2-1.

[30] I. Sukoya, R. W. Kwame, and O. Yangari, "Analysis of gender differentials in technical efficiency of smallholder rice farmers in Ashanti region of Ghana," International Scholars Journals, vol. 3, no. 2, pp. 113-121, 2016.

[31] D. Aigner, C. A. K. Lovell, and P. Schmidt, "Formulation and Estimation of Stochastic Frontier Production Function Models," Journal of Econometrics, vol. 6, pp. 21-37, 1977.

[32] W. Meeusen and J. van Den Broeck, "Efficiency Estimation from Cobb-Douglas Production Functions with Composed Error," International Economic Review, vol. 18, no. 2, p. 435, 1977, doi: $10.2307 / 2525757$.

[33] G. Battese and S. Broca, "Functional forms of stochastic frontier production functions and models for technical inefficiency effects: a comparative study for wheat farmers in Pakistan," Journal of productivity analysis, 1997.

[34] FAO, "Onion | Land \&amp; Water | Food and Agriculture Organization of the United Nations | Land \&amp; Water | Food and Agriculture Organization of the United Nations," 2019. http://www.fao.org/land-water/databases-and-software/crop-information/onion/en/ (accessed Apr. 12, 2019). 
